
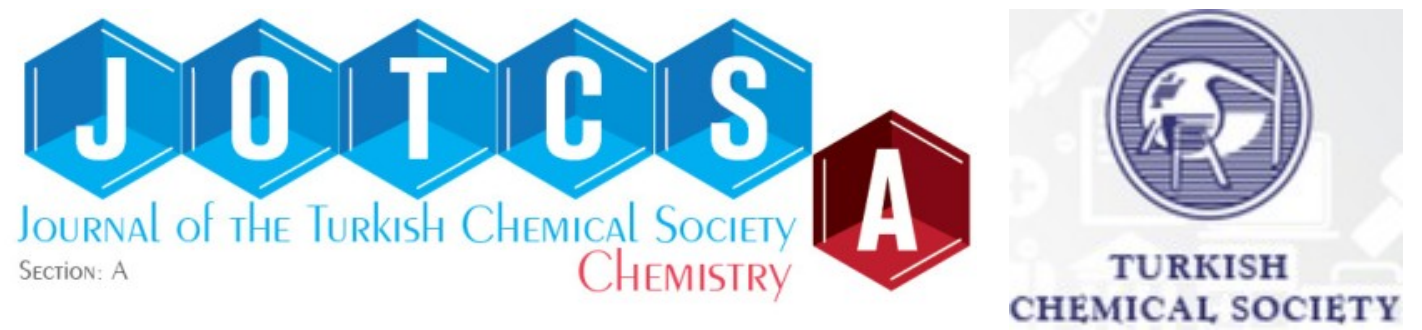

\title{
Alterations in Antioxidant Defense Systems and Metal Profiles in the Liver of Rats with Metabolic Syndrome Induced with High-Sucrose Diet
}

\author{
Özlem Alptekin $^{1 *}$ (iD, s. Seyhan Tükel ${ }^{2}$ (D), Belma Turan ${ }^{3}$ (D), Yurdun Kuyucu ${ }^{4}(D)$ \\ ${ }^{1}$ University of Cukurova, Faculty of Pharmacy, Department of Biochemistry, Adana, Turkey \\ ${ }^{2}$ University of Cukurova, Faculty of Arts \& Sciences, Department of Chemistry, Adana, Turkey \\ ${ }^{3}$ University of Lokman Hekim, Faculty of Medicine, Department of Biophysics, Ankara, Turkey \\ ${ }^{4}$ University of Cukurova, Faculty of Medicine, Department of Histology and Embryology, Adana, Turkey
}

\begin{abstract}
Metabolic syndrome (MetS) is a combination of several different metabolic disorders and considered one of the major public health problems worldwide. The underlying causes of MetS include being overweight and obesity, physical inactivity, and genetic factors. We aimed to examine the alterations in the levels of biomarkers of oxidative stress, activities of antioxidant defense enzymes, and metal contents of the liver in rats with MetS. Rats in control and MetS groups were fed with standard rat chowdrinking water and standard rat chow - 32\% sucrose solution (instead of drinking water) ad libitum for 16 weeks, respectively. Following the confirmation of MetS, antioxidant enzyme activities and malondialdehyde (MDA), 3-nitrotyrosine (3-NT), phospho-Akt (pSer473) levels were measured in the homogenates of the liver. Distributions of elements in the liver were also analyzed. The stained hepatic tissue slides were examined by light microscopy. The activities of catalase and glutathione-S-transferase were significantly decreased in MetS-group (about 15\% and 29\%, respectively) compared to the control group, while the glutathione reductase activity and MDA and 3-NT levels were significantly increased (as the levels of $78 \%, 26 \%$, and $67 \%$, respectively) $(p<0.05)$. The hepatocytes in the MetS group showed mild diffuse microvesicular steatosis. Furthermore, $\mathrm{Cu}, \mathrm{Fe}$, and $\mathrm{Mn}$ levels were significantly high in MetSgroup while $\mathrm{Zn}$ level was significantly low compared to the control group. Our results showed increased oxidative stress, impaired antioxidant defense enzyme activities, and altered metals' metabolisms which may have an important role in the pathogenesis of MetS.
\end{abstract}

Keywords: Metabolic syndrome, liver, antioxidants, oxidative stress, metals

Submitted: September 23, 2021. Accepted: November 16, 2021.

Cite this: Alptekin Ö, Tükel SS, Turan B, Kuyucu Y. Alterations in Antioxidant Defense Systems and Metal Profiles in the Liver of Rats with Metabolic Syndrome Induced with High-Sucrose Diet. JOTCSA. $2022 ; 9(1): 13-20$.

DOI: https://doi.org/10.18596/jotcsa.945582.

*Corresponding author. E-mail: oalptekin@cu.edu.tr.

\section{INTRODUCTION}

Metabolic syndrome (MetS) is a cluster of metabolic conditions, such as insulin resistance, abnormal glucose tolerance, abdominal obesity, hypertension, hypertriglyceridemia, hyperinsulinemia, hyper lowdensity lipoproteins, prothrombotic and/or proinflammatory states. Those are accepted risk factors that increase the incidence of type 2 diabetes mellitus (T2DM), non-alcoholic fatty liver disease (NAFLD), cardiovascular disease (CVD), and renal disease (1). MetS affects a significant percentage of the population and is increasingly more prevalent in developing countries, such as Turkey, where the prevalence was $26.8 \%$ in men and $38.3 \%$ in women in 2018 (2).

The pathogenesis of MetS is very complex and the underlying mechanisms of how the risk factors are affecting are not known very well yet. Imbalance of oxidant/antioxidant status may play a key role in its manifestations $(3,4)$. Oxidative damage is resulted 
from oxidative stress and disrupts redox signaling. The levels of biomarkers which are oxidative damage products from lipids, proteins and DNA are often measured for determination of the status of oxidative stress (5). The malondialdehyde (MDA) and 3-nitrotyrosine (3-NT) are the main products of oxidative damage of lipids and amino acids, respectively. Modification of protein tyrosine can result in changes of protein structure, function, and catalytic activity. The formation of reactive oxygen or nitrogen species (ROS or RNS) and reparation of oxidative damage in cells can be controlled by the antioxidant system that consists of non-enzymatic and enzymatic antioxidants (6). Superoxide dismutase (SOD), catalase (CAT), glutathione reductase (GR) and glutathione peroxidase (GPx) are the antioxidant enzymes. SOD is a metalloenzyme containing $\mathrm{Cu} / \mathrm{Zn}$ in cytosol or $\mathrm{Mn}$ in mitochondria catalyzes the formation of hydrogen peroxide from the superoxide anion radical. CAT is also a metalloenzyme containing Fe catalyzing the decomposition of hydrogen peroxide to molecular oxygen and water. GR catalyzes the reduction of glutathione disulfide (GSSG) to glutathione (GSH) by the NADPH-dependent mechanism and plays a critical role in GSH metabolism. GPx containing Se plays an important role in the reduction of hydrogen peroxide and peroxide radicals. Glutathione Stransferase (GST), that is important for detoxification of oxidative products of oxidative stress, catalyzes the conjugation of GSH to xenobiotic substrates for the cellular detoxification and excretion (7).

The major tasks of the liver include maintaining systemic glucose and lipid homeostasis through a complex hormonal system, control of transcription factors and signalling pathways. Moreover, it is especially susceptible to the damage of oxidative stress (8). Akt (PKB) is a serine/threonine-specific protein kinase and plays an important role in cell growth, survival, proliferation, and metabolism (9). Furthermore, Akt signaling plays a central role in insulin-stimulated glucose uptake in both muscle and adipose tissue in that time it inhibits glucose release from hepatocytes (10). Akt can affect further processes associated with MetS and its longterm consequences.

Experimental animal models mimicking the disease state in humans are very important to evaluate the pathophysiology of MetS in human. Genetic modification, drugs and dietary manipulation were used to induce MetS in animal models in many pieces of research (11). Diet affects whole-body metabolism so a single type of diet (high-sucrose, high-fructose or high-fat) or a combination of diets (high-sucrose/high-fat or high-fructose/high-fat) were used to induce MetS. Rat model that is the most used to investigate metabolic diseases displays the closest criterion to human MetS was induced by diet.
In some studies of MetS in humans, metal levels have been measured in biological samples such as whole blood, plasma, serum, and urine (12-15). Animal model studies are also important to determine possible changes in metal levels in different organs or tissues as early and direct indicators of many syndromes. The roles of the metals, antioxidant enzymes and products of ROS and RNS in MetS are not clear yet. In the literature, there were different experimental studies related to the MetS in which CAT and SOD activities, MDA or some metals status in serum, liver, or other tissues were measured (16-21). However, all above mentioned parameters and additionally GPx, GR and GST activities and 3-NT and phospho-Akt (pSer473) levels in the liver were not evaluated simultaneously. This study will contribute to the more accurate explanation of the mechanisms related to MetS in the liver. To the best of our knowledge, there is not any similar experimental study in the literature that determine all the abovementioned parameters in the liver of male Wistar rats in which MetS is induced with a $32 \%$ sucrose solution. In the present study, we aimed to investigate the possible association between MetS and the altered antioxidant status in terms of enzymatic activities, the levels of oxidative stress biomarkers, and morphological changes of hepatic tissue and to assess the levels of metals in the liver of rats with sucrose induced MetS.

\section{MATERIALS AND METHODS}

\section{Experimental Animals}

In this study, 2-month-old male Wistar rats $(n=16)$ were randomly separated into two groups: control $(n=6)$; and MetS $(n=10)$. Initial bodily weight of the rats was approximately $200-220 \mathrm{~g}$ in each group. They were kept on a 12-light/12-h dark cycle at $20 \pm 2{ }^{\circ} \mathrm{C}, 30-70 \%$ humidity. All experimental procedures approved by The Local Ethics Committee on Animal Experiments of Ankara University (20195-50) and they performed according to institutional guidelines.

\section{Induction and Validation of Mets in Rats}

Rats in the control group were fed with standard rat chow-drinking water and in the MetS group they fed standard rat chow-32\% sucrose solution ad libitum for 16 weeks. Bodily weight of each animal was recorded at the beginning of experimental studies then at the end of 16 weeks. Glucose tolerance and insulin resistance tests were made for control and MetS groups at the $16^{\text {th }}$ week. Fasting blood glucose and serum insulin levels were measured in blood samples were taken from the tail vein, using a glucometer (Accu-chek Nano Performa, Roche, Mannheim, Germany) and an insulin (rat) enzyme immunoassay kit (A05105; SPIBIO, Montigny le Bretonneux, France), respectively. Homeostatic Model Assessment for Insulin Resistance (HOMA-IR) was calculated according to the formula: fasting 
insulin $(\mu \mathrm{U} / \mathrm{L}) \times$ fasting glucose $(\mathrm{mmol} / \mathrm{L}) / 22.5$ (22).

The oral glucose tolerance test (OGTT) was performed to rats fasted for $12 \mathrm{~h}$. Glucose solution $(40 \%(\mathrm{w} / \mathrm{v}))$ was loaded into the stomach by a gastric catheter at a dose of $2 \mathrm{~g} / \mathrm{kg}$ bodily weight of rats. Blood glucose and serum insulin levels were measured at $0,15,30,60$, and $120 \mathrm{~min}$ after glucose loading and results were calculated from the area under the curve (AUC) of insulin and glucose.

\section{Harvesting of the Liver and Preparation of the Tissue Homogenate}

Rats were sacrificed after intraperitoneal injection of pentobarbital sodium $(30 \mathrm{mg} / \mathrm{kg})$ and then the livers were immediately excised. Some small pieces of the hepatic tissue samples were fixed in $10 \%$ formalin for histomorphological examination and remaining parts were stored at $-80{ }^{\circ} \mathrm{C}$ until using for biochemical analysis.

The liver homogenates were prepared according to our previous study (16). The homogenates were centrifuged at $10,000 \mathrm{~g}$ (Hettich Universal $30 \mathrm{RF}$, Tuttlingen, Germany) for $30 \mathrm{~min}$ at $+4{ }^{\circ} \mathrm{C}$. The supernatants were separated from precipitates then their protein concentrations were determined according to Lowry et al. by using bovine serum albumin solution as a standard (23). Before measuring SOD, CAT, GPx, GR and GST activities, the protein concentrations of supernatants were adjusted to $1 \mathrm{mg} / \mathrm{mL}$.

\section{Determination of MDA, 3-NT, and Phospho-Akt (pSer473) Levels}

The MDA level was assessed according to the method of Buege and Aust (24). The results were given as $\mu \mathrm{mol}$ MDA per milligrams of protein in supernatants. For determination of 3-NT and phospho-Akt (pSer473) levels in the liver ELISA (Enzyme linked immunosorbent assay) kits (ab116691, Abcam and RAB0011, Sigma-Aldrich) were used according to the manufacturer's instructions. The relative amount of phospho-Akt (pSer473) was calculated in the MetS group as compared to the control group.

\section{Determination of SOD, CAT, GPx, GR, and GST Activities}

SOD, CAT, GPx, GR and GST activities were determined according to Sun et al. (25), Aebi (26), Paglia and Valentine (27), Carlberg and Mannervik (28) and Habig et al. (29) by spectrophotometric means, respectively. One SOD unit was defined as the amount of enzyme that inhibits the rate of nitro blue tetrazolium (NBT) reduction by $50 \%$. The CAT activity was expressed as $\mu \mathrm{mol}$ of $\mathrm{H}_{2} \mathrm{O}_{2}$ decomposed per $\mathrm{mg}$ protein per minute. The GPx and GR activities were expressed as nmol oxidized NADPH per $\mathrm{mg}$ of protein per minute. The GST activity was given as nmol 1-chloro-2,4-dinitrobenzene (CDNB)glutathione conjugate per $\mathrm{mg}$ protein per minute.

\section{Light Microscopic Examination}

The hepatic tissue samples were fixed in $10 \%$ formalin for $72 \mathrm{~h}$ and dehydrated for paraffin embedding. The paraffin piece was cut into sections, at $5 \mu \mathrm{m}$ thickness using a microtome, then they were stained with hematoxylin and eosin (H\&E). Slides were examined and photographed with the Olympus BX 53 light microscope (Olympus Corp., Tokyo, Japan).

\section{Determination of Metallic Levels in the Liver}

The weighed liver samples were dried at $105^{\circ} \mathrm{C}$ for $120 \mathrm{~h}$, then dried tissues were digested with a $\mathrm{HClO}_{4} / \mathrm{HNO}_{3}(1: 2 ; \mathrm{v} / \mathrm{v})$ acidic mixture at $100{ }^{\circ} \mathrm{C}$ for $5 \mathrm{~h}$. The levels of $\mathrm{Ca}, \mathrm{Cu}, \mathrm{Fe}, \mathrm{Mg}, \mathrm{Mn}$, and $\mathrm{Zn}$ were determined using inductively coupled plasma optical emission spectrometry (ICP-OES; Optima 2100 DV; Perkin Elmer, Shelton, CT, USA) and $\mu \mathrm{g}$ elements per gram of dry tissue were calculated.

\section{Statistics}

The Sigma Plot software for Windows version 12.0 (Systat Software, San Jose, CA, USA) was used for the statistical analysis of the results. The results are given as mean \pm standard deviation (SD). Statistical significance was evaluated using one-way ANOVA followed by Duncan's post hoc test for comparisons between groups. A $p$-value $<0.05$ was considered to be statistically significant.

\section{RESULTS AND DISCUSSION}

Bodily weight, fasting blood glucose, plasma insulin, OGTT levels, and HOMA-IR score were measured in both control and MetS groups as indicators of MetS. As shown in Figure $1(a-b)$, sucrose administration caused significant $(p<0.05)$ increases in the following parameters: bodily weight (15\%) (a), fasting blood glucose $(43 \%)$ (b), serum insulin level $(80 \%)$ (c), HOMA-IR score (162\%) (d) and OGTT level $(51 \%)(e)$. These results indicate that the metabolic syndrome was successfully induced in rats.

As shown in Figure 2, MDA and 3-NT levels determined in the hepatic tissue from the MetS group were significantly higher than those of the control group as $26 \%$ and $67 \%$, respectively (a and b). The phospho-Akt (pSer473) level of the MetS group was similar that of the control group (Figure 2c). The elevated levels of MDA and 3-NT together with observed mild diffuse microvesicular steatosis could be associated with hepatic fibrosis and mitochondrial dysfunction, which represent critical initiating events for the development of NAFLD in the liver of MetS-rats $(15,17)$. In the literature, some studies reported that the increased 3-NT was related to steatosis in the liver which may indicate a possible involvement of peroxynitrite in the development of MetS complications $(18,30)$. In the present study, the level of phospho-Akt (pSer473) did not change significantly in the liver of rats with 
MetS compared to that of controls. Although the difference was not significant, however, a tendency to increase may be noted in the MetS group. In the literature, increased basal phospho-Akt (pSer473) level was associated with decreased mitochondrial production and increased ectopic fat accumulation and oxidative stress in the liver of mice under the high-fat-diet was reported (31). a

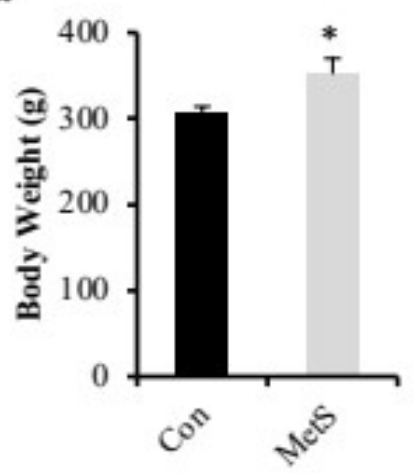

b

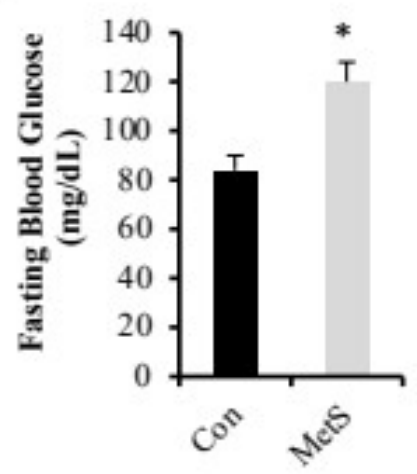

c

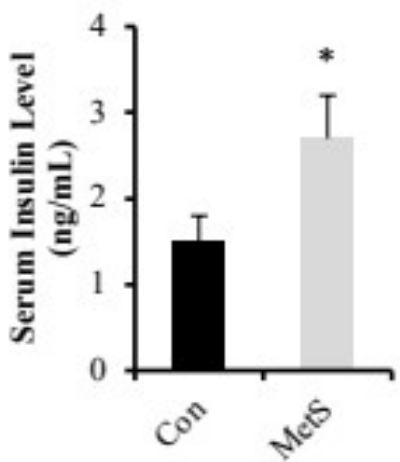

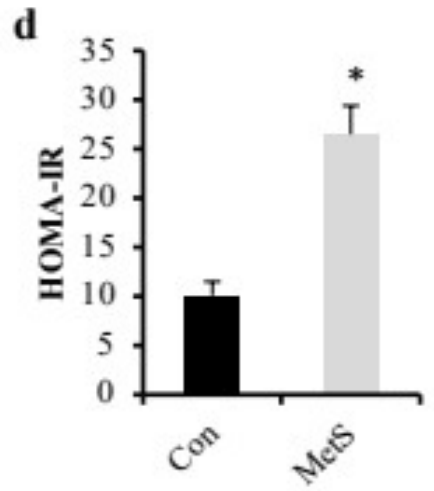

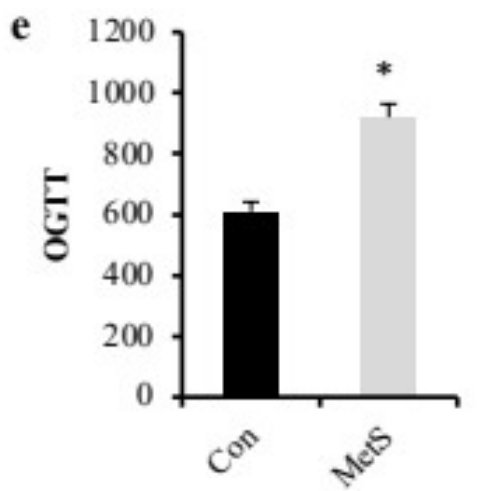

Figure 1: Bodily weight (a), fasting blood glucose concentration (b), plasma insulin level (c), HOMA-IR score (d), OGTT level (e) in control (Con) and metabolic syndrome (MetS) groups. $* p<0.05$ vs. Con group.
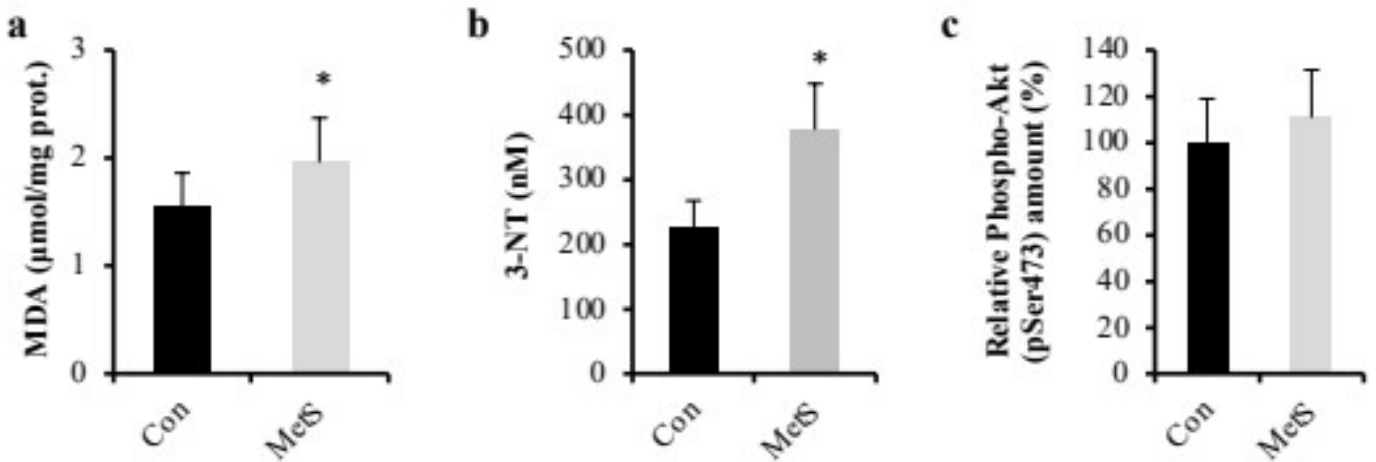

Figure 2: The levels of MDA (a), 3-NT (b), phospho-Akt (pSer473) (c) in the liver of control (Con) and metabolic syndrome (MetS) groups. $* p<0.05$ vs. Con-group.

The activities of SOD and GPx in the hepatic tissue were found similar in both MetS and control groups (Figure $3 \mathrm{a}$ and $3 \mathrm{~b}$ ). However, the CAT and GST activities were significantly low in the MetS group as a level of $15 \%$ and $29 \%$ when compared to the control group, respectively (Figure $3 c$ and $3 d$ ). On the other hand, the GR activity was significantly high in the MetS group (by $78 \%$ ) than that of the control group (Figure 3e). In this study, decreased CAT, GST activities and increased GR activity 
demonstrated oxidative stress in the MetS group. The change of antioxidant enzyme activities can be explained with (i) increasing of ROS and RNS production (20), the enzymes nitration (21), and the glycation products (3) (ii) reduced antioxidant capacity and (iii) increasing or decreasing the enzymes expressions $(8,32)$. Increased GR activity also indicated that GSH metabolism was affected from MetS. In our previous study, activities of SOD, CAT, GPx, GR were all significantly decreased in the masseter muscles of rats with MetS (16). These results demonstrated that the effects of MetS on different tissues varied depending on the metabolic functions of the tissues. In the literature, there were different results regarding changes in antioxidant enzyme activities in rats with the MetS group.
Nestorov et al. reported an increased expression of $\mathrm{Mn}-\mathrm{SOD}$ but the lack of correlation between $\mathrm{Mn}$ SOD activity and its protein level due to inactivation of the enzyme by glycation (33). However, RubioRubiz et al. reported decreased SOD activity in the liver of rats with MetS (34). Moreover, Jarukamjorn et al. reported that mRNA expression and enzymatic activity of SOD, CAT, and GPx were increased in the liver of mice fed with the high-fat high-fructose diet for 2-8 wks (35). Al Mamun et al. reported decreased CAT and SOD activities in the liver of high-carbohydrate/high-fat (HCHF) diet-fed rats (36). Although hepatic tissue with MetS was investigated, different diet, age, and animal models that were used in these studies made it difficult to compare the results directly. a
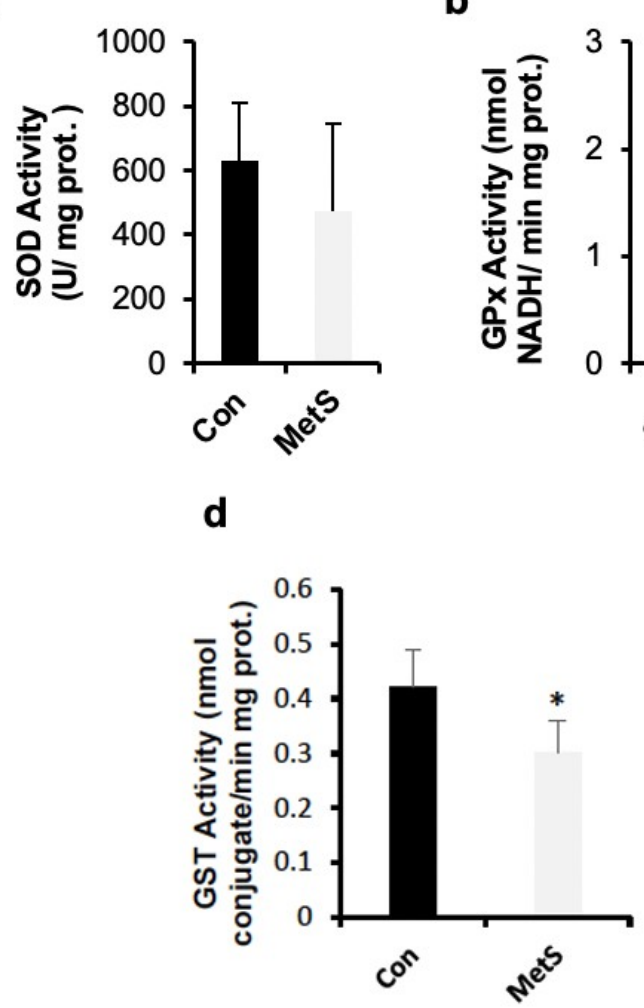

b

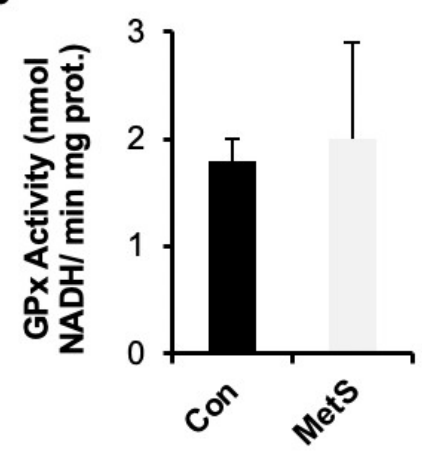

C

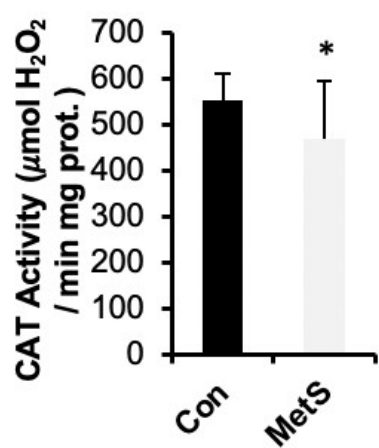

e

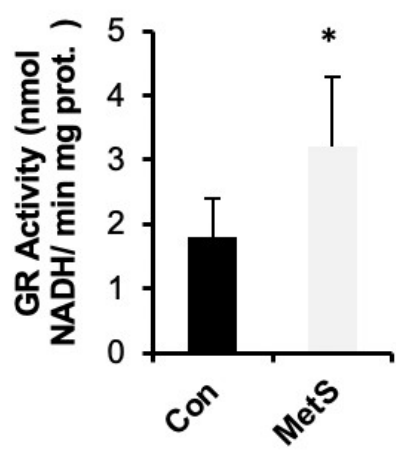

Figure 3: Antioxidant enzyme activities determined in the hepatic tissues from metabolic syndrome (MetS) group compared to the control (Con) group. SOD (a), GPx (b), CAT (c), GST (d) and GR (e) activities. $* p<0.05$ vs. Con group.

Hepatic parenchyma in the control group was consisted of stacks of anastomosing plates of hepatocytes, which were one cell thick and were separated by sinusoidal capillaries. Hepatocytes, with vesicular nucleus and the hepatocyte cytoplasm, were seen normal. Sinusoidal capillaries, the vascular channels between the plates of hepatocytes, perisinusoidal spaces, the central vein, the portal areas with hepatic artery, portal vein, and the bile duct were seen normal (Figure $4 a$ and 4b). However, hepatocytes in the MetS group showed mild diffuse microvesicular steatosis (Figure $4 \mathrm{c}$ and 4d). 


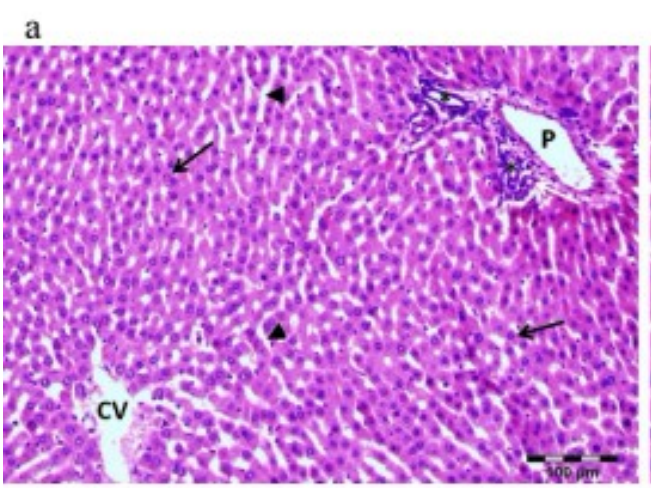

b
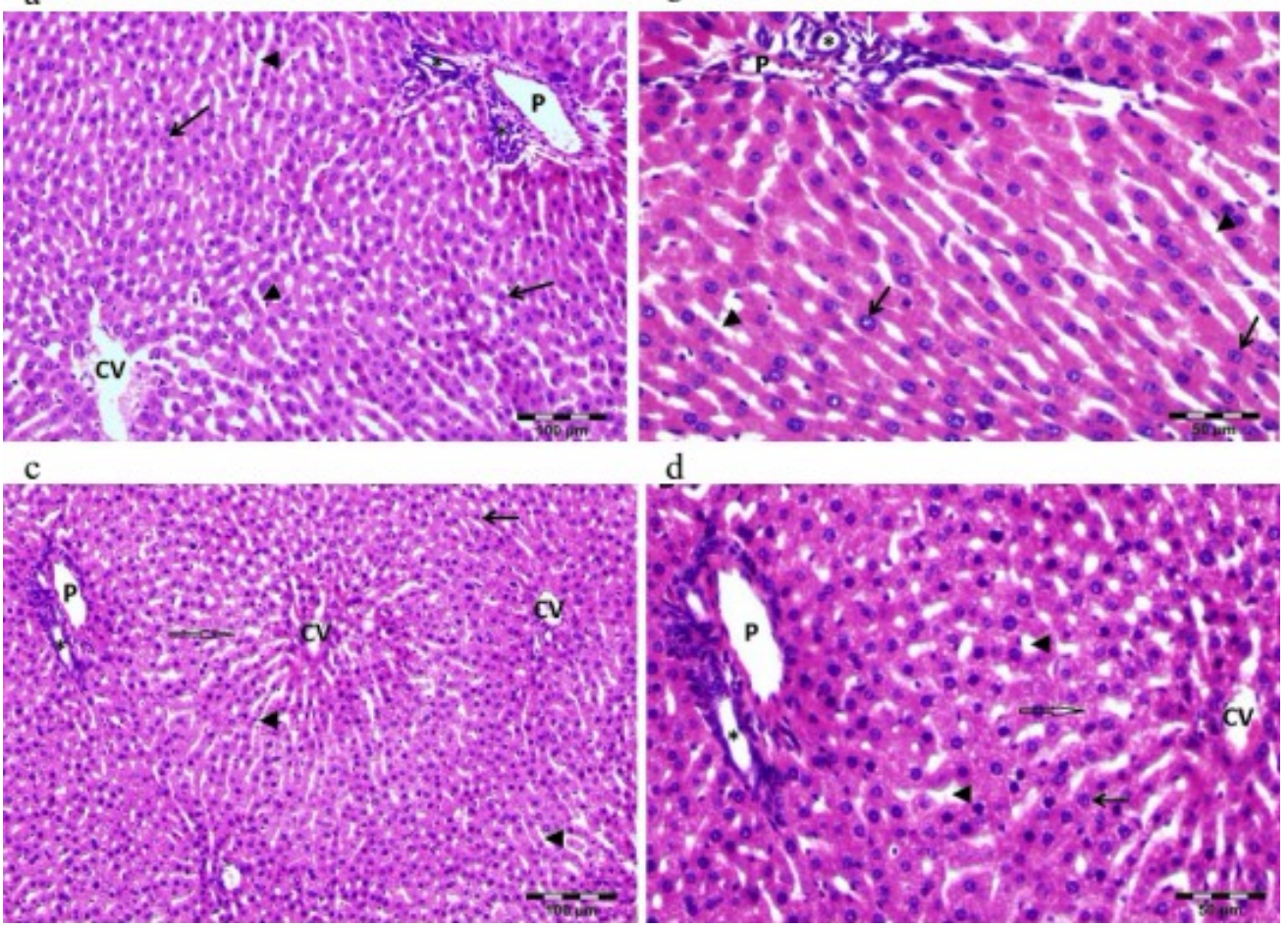

Figure 4: Control Group (4a and 4b). Metabolic Syndrome Group (4c and 4d). Hepatocytes (black arrows), sinusoidal capillaries (arrow heads), central veins (CV), portal veins (P), hepatic arteries (white arrows) and the bile ducts $\left(^{*}\right)$ are seen. Microvesicular lipid storage is indicated (empty arrows). Bars: $100 \mu \mathrm{m}(4 \mathrm{a}$ and $4 \mathrm{c})$ and $50 \mu \mathrm{m}(4 \mathrm{~b}$ and $4 \mathrm{~d})$.

Table 1: Levels of metals in the hepatic tissues of rats.

\begin{tabular}{ccc}
\hline Name of the Metals & \multicolumn{2}{c}{ Metals Levels $(\boldsymbol{\mu g} / \mathbf{g}$ dried tissue) } \\
& Con Group & MetS Group \\
\hline $\mathrm{Ca}$ & $40.7 \pm 26.5$ & $55.0 \pm 47.1$ \\
$\mathrm{Cu}$ & $4.4 \pm 0.9$ & $5.6 \pm 1.6^{*}$ \\
$\mathrm{Fe}$ & $269.1 \pm 95.1$ & $356.6 \pm 126.2^{*}$ \\
$\mathrm{Mg}$ & $269.3 \pm 42.7$ & $288.8 \pm 56.4$ \\
$\mathrm{Mn}$ & $0.4 \pm 0.3$ & $3.0 \pm 0.8^{* *}$ \\
$\mathrm{Zn}$ & $42.4 \pm 6.3$ & $35.9 \pm 8.6^{*}$ \\
\hline
\end{tabular}

The male Wistar rats in the group that had metabolic syndrome (MetS; $n=10$ rats) induced with a highsucrose diet by comparison with the normal control (Con; $n=6$ rats) group. Data are presented as mean \pm SD. ${ }^{*} p<0.05$ and ${ }^{* *} p<0.01$ compared with the Con group.

As shown in Table 1 , the levels of $\mathrm{Ca}$ and $\mathrm{Mg}$ were similar among these two groups. However, the levels of $\mathrm{Cu}, \mathrm{Fe}$, and $\mathrm{Mn}$ determined in the hepatic tissues were significantly high in MetS group compared to the control group as 1.3, 1.3 and 7.0fold, respectively. The level of $\mathrm{Zn}$ was significantly low in MetS group compared to the control group. In our study, elevated $\mathrm{Cu}, \mathrm{Fe}$, and $\mathrm{Mn}$ concentrations were indicated that MetS significantly related to their status in the liver of rats and they could lead to changes in the balance of oxidant/antioxidant status. The increased $\mathrm{Cu}$ and Fe levels in the liver of rats with MetS support the increased oxidative stress. Because $\mathrm{Cu}$ and $\mathrm{Fe}$ as redox-cycling metals are involved in the formation of ROS; the catalytic function of $\mathrm{Fe}^{2+} / \mathrm{Fe}^{3+}$ and $\mathrm{Cu}^{+} / \mathrm{Cu}^{2+}$ in Fenton reactions mediated generation of hydroxyl radical from $\mathrm{H}_{2} \mathrm{O}_{2}$ should be mentioned. As a result of
Fenton reactions, $\mathrm{H}_{2} \mathrm{O}_{2}$ concentration may be reduced and this may be another factor in the reduction of CAT activity in the liver of rats with MetS. Increased $\mathrm{Mn}$ level may disrupt normal mitochondrial function by altering membrane permeability, inhibiting ATP production, and increasing ROS (37). In the liver, formation of oxidative stress, alteration of enzymatic antioxidant defense systems, and significant changes in metal metabolism may be the cause of insulin resistance by interfering with the ability of insulin to suppress hepatic glucose production. This may result in mitochondrial dysfunction with time and finally, cause MetS. In our previous study, we found that $\mathrm{Cu}$ level increased in the masseter muscle of rats with MetS while Fe and Mn levels were like those of controls (16). In the literature, increased $\mathrm{Fe}$ and $\mathrm{Cu}$ 18 
reported in liver of rats fed a high carbohydratehigh fat diet for up to 16 weeks (38). Flores et al. reported the increased $\mathrm{Cu}$ level in serum and urine in T2DM patients as a result of the possibility of removing $\mathrm{Cu}$ from tissues (13). However, decreased plasma Cu level in a subject with MetS was reported by Parades et al. (14).

\section{CONCLUSION}

Our data have shown that the activities of antioxidant defense enzymes such as CAT and GST were significantly low in the liver of MetS-rats than that of control rats, although the levels of MDA and 3-NT were significantly high in the liver of MetSrats. However, the GR activity in the liver of MetSrats was markedly high in that group compared to that of control rats. The light microscopy analysis of the livers showed mild diffuse microvesicular steatosis in the MetS group. Furthermore, the tissue levels of $\mathrm{Cu}, \mathrm{Fe}$, and $\mathrm{Mn}$ were significantly high in MetS group while $\mathrm{Zn}$ level was significantly low compared to the control group. The impaired carbohydrate, lipid, metal and glutathione metabolisms may have important roles in the pathogenesis and progression of MetS. Increased $\mathrm{Cu}, \mathrm{Fe}$ and $\mathrm{Mn}$ levels and decreased $\mathrm{Zn}$ level may also play an important role in imbalance of oxidant/antioxidant status in the liver of rats with MetS. Considering oxidative stress as signaling markers for any dysfunction of organs in certain circumstances, its control signifies a rational curative strategy to prevent and cure hepatic diseases in MetS.

\section{CONFLICT OF INTEREST}

All authors declare no conflict of interest.

\section{REFERENCES}

1. Nicolson GL. Metabolic syndrome and mitochondrial function: Molecular replacement and antioxidant supplements to prevent membrane peroxidation and restore mitochondrial function. J Cell Biochem. $2007 \mathrm{Apr}$ $15 ; 100(6): 1352-69$. $\leq$ DOI $>$.

2. Abacl A. Data on prevalence of metabolic syndrome in Turkey: Systematic review, meta-analysis and metaregression of epidemiological studies on cardiovascular risk factors. Arch Turk Soc Cardiol. 2018; 46(7): 591-601. $\leq \mathrm{DOI}>$.

3. Vona R, Gambardella L, Cittadini C, Straface E, Pietraforte D. Biomarkers of Oxidative Stress in Metabolic Syndrome and Associated Diseases. Oxidative Medicine and Cellular Longevity. 2019 May 5;2019:1-19. <DOI $>$.

4. Rochlani Y, Pothineni NV, Kovelamudi S, Mehta JL. Metabolic syndrome: pathophysiology, management, and modulation by natural compounds. Therapeutic Advances in Cardiovascular Disease. 2017 Aug;11(8):215-25. $\leq$ DOI $>$.
5. Rytz CL, Pialoux V, Mura M, Martin A, Hogan DB, Hill $M D$, et al. Impact of aerobic exercise, sex, and metabolic syndrome on markers of oxidative stress: results from the Brain in Motion study. Journal of Applied Physiology. 2020 Apr $1 ; 128(4): 748-56$. $\leq$ DOI $>$.

6. Matés JM, Pérez-Gómez C, De Castro IN. Antioxidant enzymes and human diseases. Clinical Biochemistry. 1999 Nov;32(8):595-603. $\leq$ DOI $>$.

7. Townsend DM, Tew KD. The role of glutathione-Stransferase in anti-cancer drug resistance. Oncogene. 2003 Oct;22(47):7369-75. <DOI>.

8. Meng $R$, Zhu $D-L, B i ~ Y$, Yang $D-H$, Wang $Y-P$. Antioxidative effect of apocynin on insulin resistance in highfat diet mice. Ann Clin Lab Sci. 2011;41(3):236-43. PMID: 22075506

9. Zhu C, Schwarz P, Abakumova I, Aguzzi A. Unaltered Prion Pathogenesis in a Mouse Model of High-Fat DietInduced Insulin Resistance. Ma J, editor. PLoS ONE. 2015 Dec 14;10(12): e0144983. <DOI >.

10. Mackenzie R, Elliott B. Akt/PKB activation and insulin signaling: a novel insulin signaling pathway in the treatment of type 2 diabetes. DMSO. 2014 Feb;55. $\leq$ DOI $>$.

11. Wong SK, Chin K-Y, Suhaimi FH, Fairus A, ImaNirwana S. Animal models of metabolic syndrome: a review. Nutr Metab (Lond). 2016 Dec;13(1):65. <DOI $>$.

12. Kazi TG, Afridi HI, Kazi N, Jamali MK, Arain MB, Jalbani $\mathrm{N}$, et al. Copper, Chromium, Manganese, Iron, Nickel, and Zinc Levels in Biological Samples of Diabetes Mellitus Patients. Biol Trace Elem Res. 2008 Apr;122(1):1-18. $\leq \mathrm{DOI}>$.

13. Flores $C R$, Puga MP, Wrobel K, Garay Sevilla MaE, Wrobel K. Trace elements status in diabetes mellitus type 2: Possible role of the interaction between molybdenum and copper in the progress of typical complications. Diabetes Research and Clinical Practice. 2011 Mar;91(3):333-41. $\leq$ DOI $>$.

14. Paredes S, Matta-Coelho C, Monteiro A, Fernandes V, Marques $\mathrm{O}$, Alves M. Copper levels, calcium levels and metabolic syndrome. Rev Port Diabetes. 2016;11:99-105. $\leq \mathrm{URL}>$.

15. Freitas E, Cunha A, Aquino S, Pedrosa L, Lima S, Lima J, et al. Zinc Status Biomarkers and Cardiometabolic Risk Factors in Metabolic Syndrome: A Case Control Study. Nutrients. 2017 Feb 22;9(2):175. <DOI $>$.

16. Tükel HC, Alptekin Ö, Turan B, Delilbaşı E. Effects of metabolic syndrome on masseter muscle of male Wistar rats. Eur J Oral Sci. 2015 Dec;123(6):432-8. <DOI>.

17. Noeman SA, Hamooda HE, Baalash AA. Biochemical Study of Oxidative Stress Markers in the Liver, Kidney and Heart of High Fat Diet Induced Obesity in Rats. Diabetol Metab Syndr. $2011 \mathrm{Dec} ; 3(1): 17 . \leq \mathrm{DOI}>$.

18. Ucar F, Sezer S, Erdogan S, Akyol S, Armutcu F, Akyol $O$. The relationship between oxidative stress and nonalcoholic fatty liver disease: Its effects on the development of nonalcoholic steatohepatitis. Redox Report. 2013 Jul;18(4):127-33. <DOI>. 
19. Roncal-Jimenez CA, Lanaspa MA, Rivard CJ, Nakagawa $T$, Sanchez-Lozada LG, Jalal D, et al. Sucrose induces fatty liver and pancreatic inflammation in male breeder rats independent of excess energy intake. Metabolism. 2011 Sep;60(9):1259-70. $\leq$ DOI $>$.

20. Moreno-Fernández S, Garcés-Rimón M, Vera G, Astier J, Landrier J, Miguel M. High Fat/High Glucose Diet Induces Metabolic Syndrome in an Experimental Rat Model. Nutrients. 2018 Oct 14;10(10):1502. <DOI $>$.

21. Ghosh S, Sulistyoningrum DC, Glier MB, Verchere $C B$, Devlin AM. Altered Glutathione Homeostasis in Heart Augments Cardiac Lipotoxicity Associated with Dietinduced Obesity in Mice. Journal of Biological Chemistry. 2011 Dec;286(49):42483-93. $\leq \mathrm{DOI}>$.

22. Matthews DR, Hosker JP, Rudenski AS, Naylor BA, Treacher DF, Turner RC. Homeostasis model assessment: insulin resistance and?-cell function from fasting plasma glucose and insulin concentrations in man. Diabetologia. 1985 Jul;28(7):412-9. <DOI $>$.

23. Lowry $\mathrm{OH}$, Rosebrough NJ, Farr AL, Randall RJ. Protein measurement with the Folin phenol reagent. Journal of biological chemistry. 1951;193:265-75.

24. Buege JA, Aust SD. [30] Microsomal lipid peroxidation. In: Methods in Enzymology [Internet]. Elsevier; 1978 [cited 2021 Nov 20]. p. 302-10. $\leq$ URL $>$.

25. Sun Y, Oberley LW, Li Y. A simple method for clinical assay of superoxide dismutase. Clinical Chemistry. 1988 Mar $1 ; 34(3): 497-500 . \leq$ DOI $>$.

26. Aebi H. [13] Catalase in vitro. In: Methods in Enzymology [Internet]. Elsevier; 1984 [cited 2021 Nov 20]. p. 121-6. Available from: $\leq U R L>$.

27. Paglia DE, Valentine WN. Studies on the quantitative and qualitative characterization of erythrocyte glutathione peroxidase. The Journal of laboratory and clinical medicine. 1967;70(1):158-69. $\leq$ URL >.

28. Carlberg I, Mannervik B. Purification and characterization of the flavoenzyme glutathione reductase from rat liver. Journal of Biological Chemistry. 1975 Jul;250(14):5475-80. <DOI >.

29. Habig WH, Pabst MJ, Jakoby WB. Glutathione STransferases. Journal of Biological Chemistry. 1974 Nov;249(22):7130-9. $\leq \mathrm{DOI}>$.
30. Mercuri F, Tonutti L, Taboga C, Ceriello A, Assaloni R, Motz $E$, et al. Detection of nitrotyrosine in the diabetic plasma: evidence of oxidative stress. Diabetologia. 2001 Jul $1 ; 44(7): 834-8$. $\leq$ DOI $>$.

31. Liu H-Y, Hong T, Wen G-B, Han J, Zuo D, Liu Z, et al. Increased basal level of Akt-dependent insulin signaling may be responsible for the development of insulin resistance. American Journal of Physiology-Endocrinology and Metabolism. 2009 Oct;297(4):E898-906. <DOI>.

32. Pereira ENG da S, Silvares RR, Flores EEI, Rodrigues $\mathrm{KL}$, Ramos IP, da Silva IJ, et al. Hepatic microvascular dysfunction and increased advanced glycation end products are components of non-alcoholic fatty liver disease. Gracia-Sancho J, editor. PLoS ONE. 2017 Jun 19;12(6):e0179654. $\leq \mathrm{DOI}>$.

33. Nestorov J, Glban AM, Mijušković A, Nikolić-Kokić A, Elaković I, Veličković $\mathrm{N}$, et al. Long-term fructose-enriched diet introduced immediately after weaning does not induce oxidative stress in the rat liver. Nutrition Research. 2014 Jul;34(7):646-52. $\leq$ DOI $>$.

34. Rubio-Ruiz M, Guarner-Lans V, Cano-Martínez A, DíazDíaz E, Manzano-Pech L, Gamas-Magaña A, et al. Resveratrol and quercetin administration improves antioxidant defenses and reduces fatty liver in metabolic syndrome rats. Molecules. 2019 Apr 3;24(7):1297. <DOI>.

35. Jarukamjorn $\mathrm{K}$, Jearapong $\mathrm{N}$, Pimson $\mathrm{C}$, Chatuphonprasert W. A High-Fat, High-Fructose Diet Induces Antioxidant Imbalance and Increases the Risk and Progression of Nonalcoholic Fatty Liver Disease in Mice. Scientifica. 2016;2016:1-10. <DOI $>$.

36. Mamun MdAA, Faruk Md, Rahman MdM, Nahar K, Kabir $F$, Alam MA, et al. High Carbohydrate High Fat Diet Induced Hepatic Steatosis and Dyslipidemia Were Ameliorated by Psidium guajava Leaf Powder Supplementation in Rats. Evidence-Based Complementary and Alternative Medicine. 2019 Feb 3;2019:1-12. <DOI>.

37. Li L, Yang $X$. The Essential Element Manganese, Oxidative Stress, and Metabolic Diseases: Links and Interactions. Oxidative Medicine and Cellular Longevity. 2018;2018:1-11. $\leq$ DOI $>$.

38. Kalita H, Hazarika A, Devi R. Withdrawal of HighCarbohydrate, High-Fat Diet Alters Status of Trace Elements to Ameliorate Metabolic Syndrome in Rats With Type 2 Diabetes Mellitus. Canadian Journal of Diabetes. 2020 Jun;44(4):317-326.e1. $\leq \mathrm{DOI}>$. 